\title{
Geochemical and geophysical monitoring of thermal waters in Slovenia in relation to seismic activity
}

\author{
Andreja Popit $\left({ }^{1}\right)$, Janja Vaupotič $\left({ }^{1}\right)$ and Tadej Dolenec $\left({ }^{2}\right)$ \\ (') Jožef Stefan Institute, Ljubljana, Slovenia \\ $\left.{ }^{2}\right)$ Faculty of Natural Sciences and Engineering, University of Ljubljana, Ljubljana, Slovenia
}

\begin{abstract}
Pre-seismic related strains in the Earth's crust are the main cause of the observed geophysical and geochemical anomalies in ground waters preceding an earthquake. Posočje Region, situated along the Soča River, is one of the most seismically active areas of Slovenia. Our measuring stations close to the Posočje Region were installed in the thermal springs at Bled in 1998 and at Zatolmin in 1999. Since the beginning of our survey, radon concentration, electrical conductivity and water temperature have been measured continuously once every hour. In May 2002, the number of geochemical parameters monitored was extended to ionic concentration, $p H$ and $E h$, which are analysed once a month. Before seeking a correlation between geochemical and geophysical anomalies with seismic events, the influence of meteorological (atmospheric precipitation, barometric pressure) and hydrological (water table of the Tolminka River) factors on observed anomalies were studied. Results at Zatolmin showed that some radon variation during the period from June to October 2002 may be related to seismic activity and not only to meteorological effects.
\end{abstract}

Key words radon - electrical conductivity - ions thermal springs - earthquakes

\section{Introduction}

Significant variations in geophysical and geochemical parameters in soil gas and natural springs have been detected prior to or during earthquakes. The observed geophysical phenomena include variations in water level in deep wells, hydrostatic pressure, water flow rate from wells, electrical conductivity and water temperature. The most frequently studied geochemical phenomena have been concentrations of dissolved gas and ions in groundwater and variations in concentra-

Mailing address: Dr. Andreja Popit, Jožef Stefan Institute, Jamova 39, 1000 Ljubljana, Slovenia; e-mail: andreja.popit@ijs.si tions of crustal and mantle volatiles in ground gases. (Wakita, 1978; King, 1980; Nakamura and Wakita, 1985; Wakita et al., 1985, 1986; Thomas, 1988; King et al., 1994; Koch and Heinicke, 1994; Dongarra et al., 1995; Heinicke et al., 1995; Igarashi et al., 1995; Shimizu et al., 1996; Monnin and Seidel, 1997; Bella et al., 1998; Di Bello et al., 1998; Woith et al., 1998; Singh et al., 1999; Zhang, 1999; Biagi et al., 2000; Heinicke et al., 2000; Favara et al., 2001; Koch et al., 2003).

Stress/strain fields have been reported to generate geochemical and geophysical anomalies (King, 1978, 1986, 1989; Wakita et al., 1985, 1986; Igarashi et al., 1995; Zhang, 1999; Biagi et al., 2000). Even small strains are able to do so because they can be greatly amplified at pre-existing faults and fractures, where pre-existing stresses may be already near the critical levels and where pore fluids are abundant. The threshold strain changes required to cause the observed earthquake-related anomalies were estimated to be $\sim 10^{-8}$, which is comparable with tidal strain 
amplitudes (King, 1986). Wakita et al. (1986) and King (1989) indicated that chemical precursor signals are detectable especially in faults and at intersections of faults.

Much evidence demonstrates the major role of crustal fluids of deep origin in the earthquake cycle (Varhegyi et al., 1986; Toutain and Baubron 1999). Geochemical and geophysical anomalies are due to the slow growth of small cracks in the crust caused by stress corrosion by groundwater. Associated micro-fracturing of aquifers may cause mixing of fluids from two or more chemically distinct aquifers (Thomas, 1988; Igarashi et al., 1995; Singh et al., 1999; Heinicke et al., 2000). The exposure of fresh rock surfaces, resulting from mineral fracture, causes leaching of minerals with groundwater and allows the escape of trapped gases from the rock matrix (Thomas, 1988). Thus, geochemical anomalies are strongly dependent on local conditions such as rock type, stress/strain field, degree of water saturation of rock pores, etc.

Several thermal springs and wells have been reported to discharge mixtures of deep crustal fluids and shallow meteoric components, and precursory changes in fluid composition were shown to be the result of increasing contributions of the deep component to the total flow (Thomas, 1988).

Advection of carrier gases, such as $\mathrm{CO}_{2}$ and $\mathrm{CH}_{4}$, may be the main migration process for transport of trace gases $(\mathrm{Rn}, \mathrm{He})$ toward the Earth's surface. In contrast to gas advection, transport mechanisms of endogenous gases by gas diffusion or by water advection (unless under rare conditions of high-velocity resurgent water) are usually far too slow to cause the observed geochemical anomalies. Bubble movement through micro-fractured rocks (fracture aperture of 0.01 to $10 \mathrm{~mm}$ at depths of thousands of metres) appears to be an effective mode of rapid (gas velocities of the order of 10 to $1000 \mathrm{~m}$ per day) and long-distance gas migration. The evolution from bubble regimes to continuous phase flow and vice versa is due to gas pressure and fracture width changes, which provide the most suitable mechanism for explaining surface geochemical anomalies linked to seismo-tectonic processes (Varhegyi et al., 1986; Dongarra et al., 1995; Etiope and Martinelli, 2002). A significant correlation between $\mathrm{Rn}$ and
$\mathrm{CO}_{2}$ in spring gas was found in Vogtland, Germany (Heinicke et al., 1995; Koch et al., 2003) and in the Southern Apennines, Italy (Di Bello et al., 1998). Therefore, it should be useful in earthquake prediction research to continuously monitor springs that are abundant in $\mathrm{CO}_{2}$ (Koch and Heinicke, 1994).

Geothermal waters are in contact with crustal rocks at various depths. This is why spring gases might be more representative of the local environment than soil gases. Spring gases are much more enriched with deep gases and only slightly contaminated by atmospheric gases and have been proved to be better earthquake precursors (Toutain and Baubron, 1999).

The first geochemical monitoring in Slovenia connected with seismic activity was carried out on thermal waters in the Ljubljana Basin from 1981-1982 by measuring radon concentrations (Zmazek et al., 2000). In 1999, radon measurements were extended to other thermal waters in NW and E Slovenia (Zmazek et al., 2002a) and to soil gas along a presumed fault in the Krško Basin (Zmazek et al., 2002b, 2003). In addition to continuous (once per hour) measurements of radon concentration, electrical conductivity and water temperature were monitored, and gas was analysed monthly for He isotopes.

Geochemical and geophysical monitoring in thermal water at Zatolmin and Bled (both in NW Slovenia) was extended from May 2002. Besides continuously (once per hour) measured radon concentration, electrical conductivity and water temperature, ionic concentration, $\mathrm{pH}$ and $\mathrm{Eh}$ in the springs were also analysed once per month. The aim of our investigation was to study changes in geochemical and geophysical parameters in thermal springs in relation to seismic activity.

\section{Geotectonic and seismogenic setting of Slovenia}

The geotectonic position of the Slovenian territory is relatively well understood within the framework of the plate tectonic model. The recent structural pattern is a cumulative result of Tethyan evolution, where recent dynamics is determined by the closure of the Tethys and the collision of several lithospheric units. Slovenia 
lies at the junction of three tectonic plates (European, Adriatic and Tiszian), which were amalgamated during the Tertiary period. The seismicity is not concentrated along the primary plate boundaries, but is rather spread in a broad zone along their deformed rims (Poljak et al., 2000).

There is general agreement between the tectonic pattern and its geological dynamics with the type of seismicity in a particular area. Thus, seismogenic areas (Eastern Alps, Southern Alps, Friuli Region, external Dinarides and Transdanubian Range) generally coincide with the main geotectonic units (Poljak et al., 2000).

Our monitoring stations are installed at two thermal springs (fig. 1). The first is located at Bled and wells on the Bled fault on the eastern side of Lake Bled $(46.37 \mathrm{~N}, 14.11 \mathrm{E})$ which belongs to Southern Alps. The thermal water springs from a deep Triassic carbonate reservoir and rises through Oligocene clay and shallower Quaternary lake and glacial sediment. The thermal water at Zatolmin springs from Cretaceous limestone at the fault in the Cave under the Devil's bridge $(46.20 \mathrm{~N}, 13.74 \mathrm{E})$ on the southern edge of the Southern Alps, close to the bor- der with the external Dinarides. Both waters belong to calcium-magnesium-hydrocarbonatesulphate water type.

The Southern Alps are characterised by regional thrusts from the north to the south and a number of regional faults in a NW-SE direction. These faults originate from the Paleogene external Dinaric tectonic evolution and they are superimposed by the Neogene Southern Alps thrusts. They were reactivated in the post-Neogene period. The seismicity of this zone is moderate: the strongest shock occurred in 1895 and damaged the city of Ljubljana (intensity VIII-IX MSK) (Poljak et al., 2000).

\section{Analytical methods}

Radon concentration is measured continuously with a Barasol MC 450 probe (Algade, France). Radon enters the detection chamber through a filter, which prevents radon decay products from entering. The detection unit is a solid-state silicon detector. The measurement is carried out by gross alpha counting. The counts were integrated over an hour. In addition to

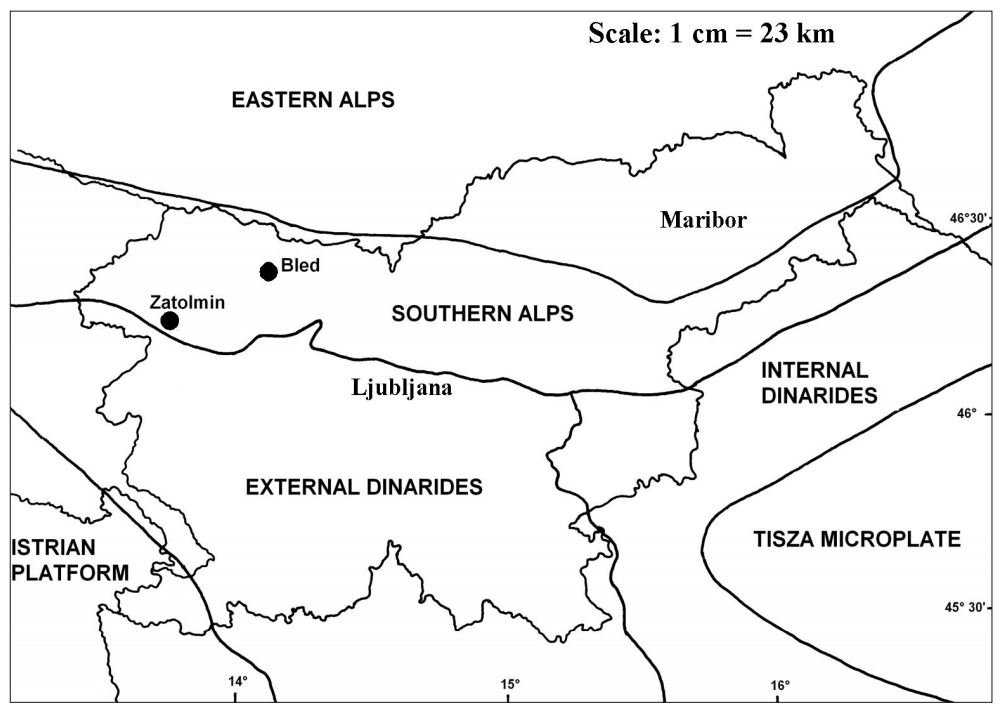

Fig. 1. Geotectonic situation of Slovenia and locations of the thermal springs at Zatolmin and Bled. 
measurement of radon, water temperature is measured over the same time periods. The sensitivity of the radon detector is $50 \mathrm{Bqm}^{-3}$, and temperature is measured to an accuracy of $\pm 0.01^{\circ} \mathrm{C}$.

Conductivity and water temperature are measured once per hour with EC 350 Electrical Conductivity Sensor (Greenspan, Australia), employing an electromagnetic field for measuring conductivity. An increase in charged ion mobility or concentration causes a decrease in resistivity and a corresponding increase in the output of the EC sensor. Water temperature is monitored by a separate sensor, which provides both a temperature output and a signal to normalise and temperature compensate the EC output. The sensitivities for the EC and temperature sensor are $0.01 \mu \mathrm{Scm}^{-1}$ and $0.01{ }^{\circ} \mathrm{C}$, respectively. The temperature measured with the EC sensor was used for the interpretation.

$E h$ and $p H$ are measured by portable redox combination electrodes (Mettler-Toledo) in situ once per month.

Water samples for cation analyses are collected once per month. Dissolved cation concentrations are analysed in the ACTLABS laboratory in Canada by Inductively Coupled Plasma Mass Spectrometry (ICP/MS).

Meteorological (average daily air temperature and barometric pressure, daily atmospheric precipitation) and hydrological data (daily average water table of the Tolminka River) were provided by the Environmental Agency of the Republic of Slovenia (ARSO), Office of Meteorology and Office of Seismology.

Seismological data were obtained from ARSO, Office of Seismology.

\section{Results and discussions}

Geochemical and geophysical monitoring in relation to seismic events was performed in two Slovenian thermal waters. Our research was focused primarily on precursory changes observed in radon concentration, water temperature, electrical conductivity, concentrations of dissolved ions, $p H$ and $E h$. Non-seismic interferences by meteorological (average daily barometric pressure and daily atmospheric precipitation) and hydrological parameters (daily aver- age water table of the Tolminka River) were studied.

Changes in observed geochemical and geophysical parameters exceeding two standard deviations $(2 \sigma)$ from the mean value were considered anomalies (Heinicke et al., 1995; Di Bello et al., 1998; Planinić et al., 2001; Virk and Walia, 2001), according to the normal distribution of measurements, where $95 \%$ of the observations are contained in the interval $\pm 2 \sigma$ from the mean value. Biagi et al. (2000) labelled each ion or gas concentration signal with amplitude greater than $3 \sigma$ as an irregularity.

\subsection{Measuring station at Zatolmin}

The thermal spring at Zatolmin is located in a natural cave along the Tolminka River, which overflows it constantly, but more intensively during heavy rains. This spring is characterised by $\mathrm{CO}_{2}$ bubbling activity. The average water temperature and its standard deviation $( \pm \sigma)$ between May 2002 and April 2003 was $21.5 \pm 0.8^{\circ} \mathrm{C}$. Probes for radon and electrical conductivity measurements are installed in the spring-water at the bottom of the cave.

The average electrical conductivity and radon concentration (both $\pm \sigma$ ) in this thermal spring between May 2002 and April 2003 were $754 \pm 47 \mu \mathrm{Scm}^{-1}$ and $33.4 \pm 19 \mathrm{kBqm}^{-3}$, respectively. Variations in radon concentration, electrical conductivity and water temperature showed significant temporal fluctuations, resulting mainly from atmospheric precipitation. These variations were distinguished from those which could be earthquake related.

Electrical conductivity is a function of both ion concentration and water temperature. The correlation coefficients between electrical conductivity and calcium, potassium and silicon concentration were $0.88,0.98$ and 0.79 , respectively. The linear trends of electrical conductivity and water temperature curves (fig. 2) were interrupted during the periods of heavy rain, when the water level of the torrential Tolminka River increased and heavy mixing of both waters occurred. These events are characterised by an instant decrease in water temperature, electrical conductivity and dissolved ion concentra- 


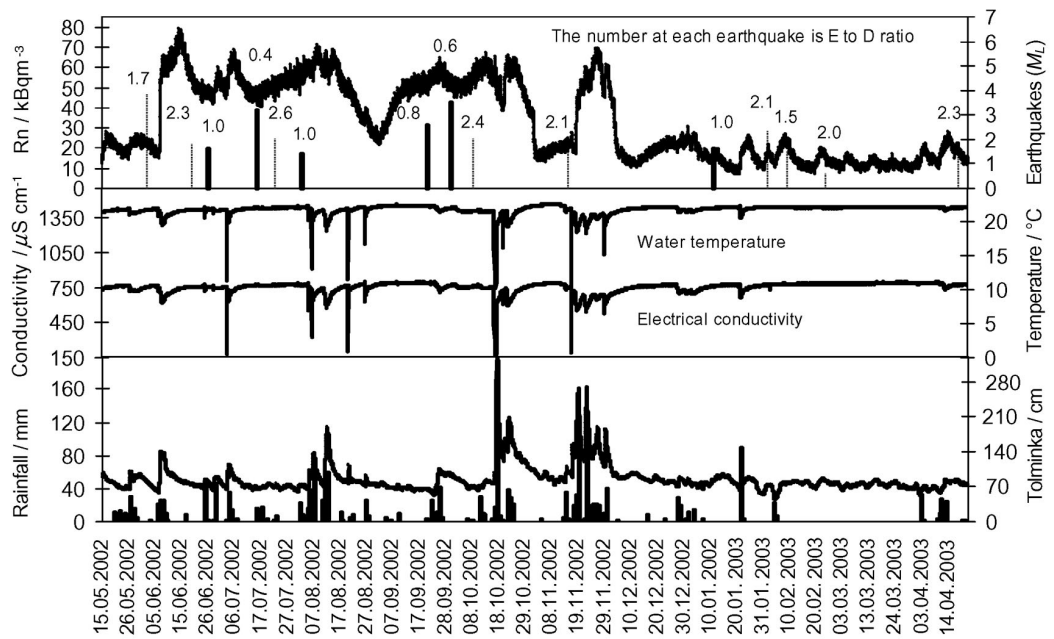

Fig. 2. Geochemical data measured in the thermal spring at Zatolmin between May 2002 and April 2003. The first diagram (starting from the top) shows radon concentration $\left(\mathrm{kBqm}^{-3}\right)$ and earthquakes $\left(M_{L}\right)$. E is the distance between the measuring station and the epicentre, while is $D$ the strain radius. Earthquakes with $E / D \leq 1$ are drawn with bold lines and those with $E / D>1$ with dashed lines. The second diagram shows electrical conductivity $\left(\mu \mathrm{Scm}^{-1}\right)$ and water temperature $\left({ }^{\circ} \mathrm{C}\right)$, and the third diagram shows rainfall $(\mathrm{mm})$ and the level of the Tolminka River $(\mathrm{cm})$.

Table I. List of earthquakes near the thermal spring at Zatolmin and Bled in the period from May 2002 to April 2003. $E(\mathrm{~km})$ is the distance between the measuring station and the epicentre, while $D(\mathrm{~km})$ is the radius of the precursory manifestation zone. Earthquakes with $(E / D \leq 1)$ are written bold.

\begin{tabular}{cccccccc}
\hline \hline Date & $\begin{array}{c}\text { Time } \\
\text { (UTC) }\end{array}$ & Latitude & Longitude & $M_{L}$ & $E$ & $D$ & $E / D$ \\
\hline 22.05 .2002 & $17: 30$ & 46.34 & 14.09 & 0.9 & $4 \mathrm{SW}$ & 2 & 2.0 \\
07.06 .2002 & $12: 38$ & 46.32 & 14.11 & 1.2 & $6 \mathrm{~S}$ & 3 & 2.0 \\
02.06 .2002 & $13: 37$ & 45.64 & 14.24 & 3.8 & $73 \mathrm{SE}$ & 43 & 1.7 \\
19.06 .2002 & $19: 07$ & 46.14 & 13.59 & 1.8 & $14 \mathrm{SW}$ & 6 & 2.3 \\
$\mathbf{2 6 . 0 6 . 2 0 0 2}$ & $\mathbf{1 1 : 1 3}$ & $\mathbf{4 6 . 2 4}$ & $\mathbf{1 3 . 7 0}$ & $\mathbf{1 . 6}$ & $\mathbf{5 ~ N W}$ & $\mathbf{5}$ & $\mathbf{1 . 0}$ \\
$\mathbf{1 5 . 0 7 . 2 0 0 2}$ & $\mathbf{0 9 : 0 4}$ & $\mathbf{4 6 . 2 9}$ & $\mathbf{1 3 . 6 9}$ & $\mathbf{3 . 2}$ & $\mathbf{1 0 ~ \mathbf { ~ W }}$ & $\mathbf{2 4}$ & $\mathbf{0 . 4}$ \\
22.07 .2002 & $18: 19$ & 46.31 & 13.59 & 2.0 & $18 \mathrm{NW}$ & 7 & 2.6 \\
$\mathbf{0 2 . 0 8 . 2 0 0 2}$ & $\mathbf{0 2 : 0 9}$ & $\mathbf{4 6 . 2 2}$ & $\mathbf{1 3 . 7 6}$ & $\mathbf{1 . 4}$ & $\mathbf{4 ~ N E}$ & $\mathbf{4}$ & $\mathbf{1 . 0}$ \\
$\mathbf{2 0 . 0 9 . 2 0 0 2}$ & $\mathbf{1 2 : 1 9}$ & $\mathbf{4 6 . 1 2}$ & $\mathbf{1 3 . 6 6}$ & $\mathbf{2 . 6}$ & $\mathbf{1 0 ~ S W}$ & $\mathbf{1 3}$ & $\mathbf{0 . 8}$ \\
$\mathbf{3 0 . 0 9 . 2 0 0 2}$ & $\mathbf{0 2 : 4 8}$ & $\mathbf{4 6 . 3 3}$ & $\mathbf{1 3 . 6 1}$ & $\mathbf{3 . 5}$ & $\mathbf{1 8 ~ N W}$ & $\mathbf{3 2}$ & $\mathbf{0 . 6}$ \\
08.10 .2002 & $22: 24$ & 46.34 & 13.63 & 2.0 & $17 \mathrm{NW}$ & 7 & 2.4 \\
15.11 .2002 & $09: 15$ & 46.12 & 13.55 & 2.1 & $17 \mathrm{SW}$ & 8 & 2.1 \\
$\mathbf{1 1 . 0 1 . 2 0 0 3}$ & $\mathbf{1 4 : 3 2}$ & $\mathbf{4 6 . 2 4}$ & $\mathbf{1 3 . 7 7}$ & $\mathbf{1 . 6}$ & $\mathbf{5} \mathbf{~ N E}$ & $\mathbf{5}$ & $\mathbf{1 . 0}$ \\
02.02 .2003 & $01: 43$ & 46.26 & 13.48 & 2.3 & $21 \mathrm{NW}$ & 10 & 2.1 \\
09.02 .2003 & $23: 22$ & 46.25 & 13.70 & 1.5 & $6 \mathrm{NW}$ & 4 & 1.5 \\
24.02 .2003 & $19: 38$ & 46.22 & 13.79 & 0.6 & $4 \mathrm{NE}$ & 2 & 2.0 \\
\hline
\end{tabular}




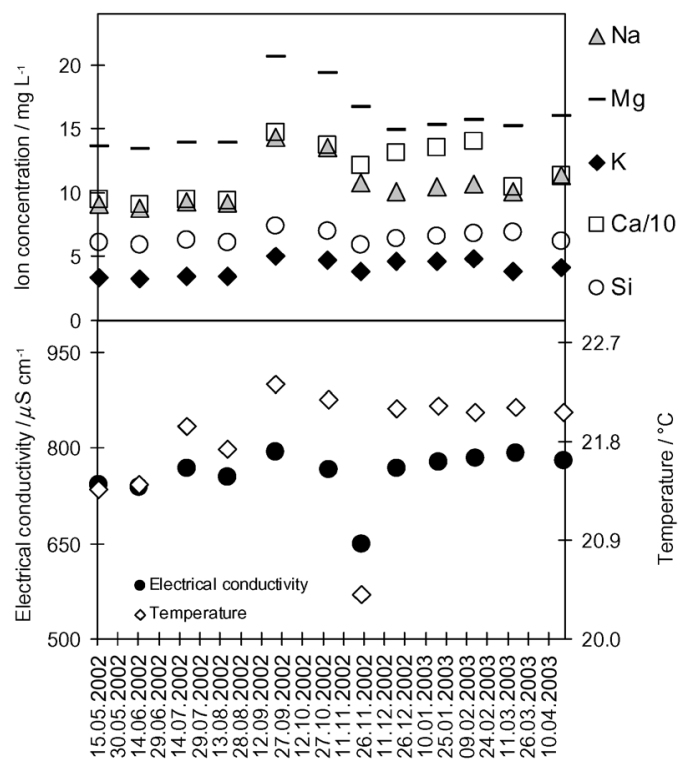

Fig. 3. Ion concentrations $\left(\mathrm{mgL}^{-1}\right)$, electrical conductivity $\left(\mu \mathrm{cm}^{-1}\right)$ and water temperature $\left({ }^{\circ} \mathrm{C}\right)$ in the thermal spring at Zatolmin between May 2002 and April 2003.

tion due to dilution of spring water with river water. The correlation coefficient between water temperature and level of the Tolminka River was -0.75 . The correlation coefficient between magnesium concentration in the Tolminka River and in the spring water was 0.60 and for silicon, 0.62. The $\mathrm{Ca}, \mathrm{K}, \mathrm{Na}, \mathrm{Mg}$ and $\mathrm{Si}$ concentrations increased by up to $50 \%$ of their initial values during the period from the middle of August to the end of September 2002 (fig. 3), and then decreased to approximately the original values by November 2002. Electrical conductivity showed a similar trend (fig. 3 ). In the period from the middle of August to the end of September 2002 there was only a small amount of rainfall, while in the period from September to November 2002, precipitation was more intense, which is evident also by the increase in Tolminka level (fig. 2).

The $p H$ and $E h$ values measured monthly from March to May 2003 were relatively stable, with average values of 6.9 and $250 \mathrm{mV}$, respectively. Small variations in $p H$ could be ex- plained by dilution of spring water with rain water, or by dissolved $\mathrm{CO}_{2}$, which lowers the $p H$, and dissolved $\mathrm{CH}_{4}$, which increases $p H$ by stripping $\mathrm{CO}_{2}$.

During the monitoring period between May 2002 and April 2003, six earthquakes of magnitude $M_{L}$ between 1.4 and 3.5 occurred in the vicinity of the thermal spring (fig. 2, table I). The distances from the spring to their epicentres $(E)$ were shorter than the strain radii $(D)$ that define the area in which the effects of the earthquake are, in principle, detectable according to the empirical formula: $D=10 \exp \left(0.43 M_{L}\right)$, introduced by Dobrovolsky (1979). In the period between June and October 2002 when five of the earthquakes with $E / D$ ratio equal to or below 1 occurred, radon concentration significantly increased, while in the period between January and April 2003, with three earthquakes of $M_{L}$ between 1.5 and 2.1 and $E / D$ ratios greater than 1 , radon level was much lower. This fact favours the theory of the stress-strain field defined by Dobrovolsky.

Two decreases of radon concentration from 27 to $15 \mathrm{kBqm}^{-3}$, which occurred between May 17 and June 6, 2002, could be explained by dilution of thermal water with river water as a consequence of rainfall (fig. 2). At the same time water temperature also decreased. Radon concentration correlated positively with water temperature until June 6, 2002. Between June 7 and June 10, 2002 the positive correlation between radon concentration and water temperature changed (fig. 4). Radon concentration increased significantly during the heavy precipitation, when the level of the Tolminka River increased and water temperature decreased. The first radon anomaly of $2 \sigma$ above the average value occurred twelve days before the earthquake of $M_{L}=1.6$ (fig. 4). The distance from the measuring station to the epicentre corresponded to the strain radius $(E / D=1)$. Dilution of radon concentration due to rainfall was insignificant, so that the radon anomaly might reflect changes in the regional stress field preceding the earthquake. Radon concentration began to decrease soon after it reached the value $2 \sigma$ above the average and continued to do so until the earthquake, which might be attributed to the stress relaxation prior to the earthquake and 


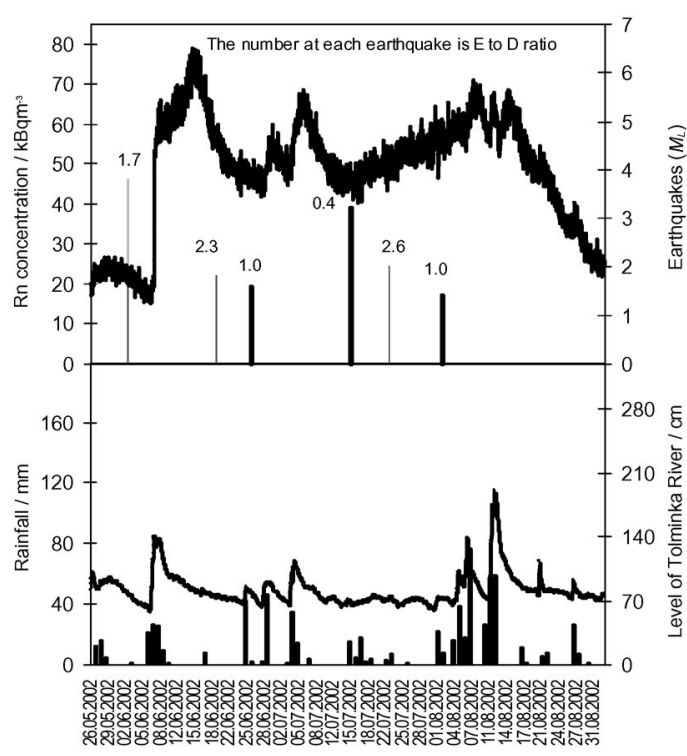

Fig. 4. $\mathrm{Rn}$ concentration $\left(\mathrm{kBqm}^{-3}\right)$, earthquakes $\left(M_{L}\right)$, rainfall $(\mathrm{mm})$ and the level of the Tolminka River $(\mathrm{cm})$ in the thermal spring at Zatolmin between May and August 2002.

some subsequent sealing of micro-cracks leading to decreased radon emanation (King, 1989; Igarashi et al., 1995).

A second increase in radon level at the beginning of July 2002 started at the same time as the increase in water level and decrease in water temperature (figs. 2 and 4). A radon concentration of $1.8 \sigma$ over the average value was observed nine days before an earthquake of $M_{L}=3.2$. The distance from the measuring station to the epicentre was shorter than the strain radius $(E / D=0.4)$. Soon after the peak in radon concentration was reached, it decreased until the seismic event occurred. This decrease might be explained by stress relaxation associated with the earthquakes and not by dilution of thermal water with rainwater, because there was no rainfall during that period.

Subsequently, radon concentration increased, in spite of the small amount of precipitation and dilution of spring water with rainwater (figs. 2 and 4$)$. It reached $1 \sigma$ above the average value at the time of an earthquake of $M_{L}=1.4$. The distance from the measuring station to the epicentre

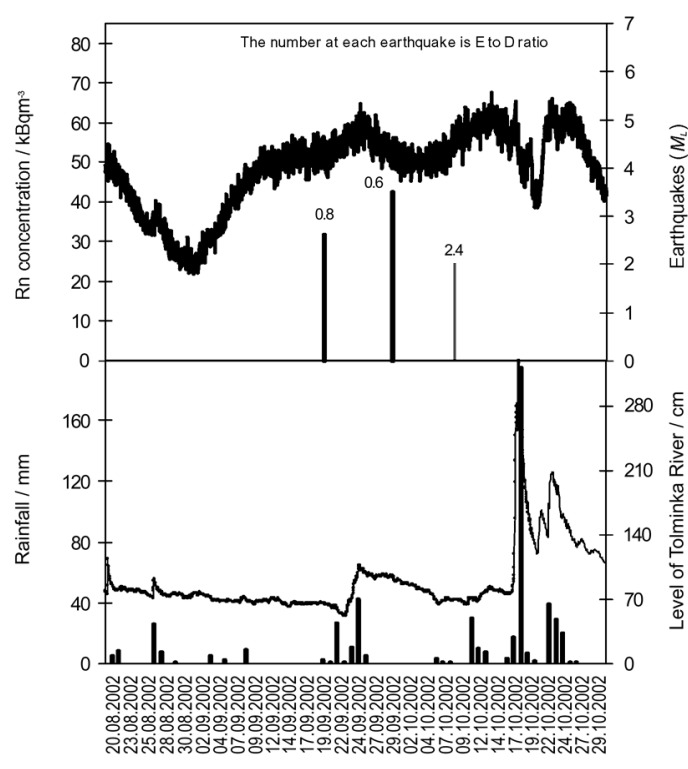

Fig. 5. $\mathrm{Rn}$ concentration $\left(\mathrm{kBqm}^{-3}\right)$, earthquakes $\left(M_{L}\right)$, rainfall $(\mathrm{mm})$ and the level of the Tolminka River $(\mathrm{cm})$ in the thermal spring at Zatolmin between $\mathrm{Au}-$ gust and October 2002.

corresponded to the strain radius $(E / D=1)$. A radon anomaly of $1.96 \sigma$ was reached six days after this earthquake, coinciding with the start of heavy precipitation. Soon, the torrential Tolminka River caused violent mixing of thermal water with cold river water. This is evident from the decreases in water temperature and radon concentration. Radon reached its minimum value one month after the last radon anomaly of $2 \sigma$.

Radon concentration again started to increase after September 1, 2002, when there was no significant rainfall, and reached $1 \sigma$ above the average value at the time of an earthquake of $M_{L}=$ $=2.6$ (figs. 2 and 5). The distance from the measuring station to the epicentre was shorter than the strain radius $(E / D=0.8)$. The radon concentration reached its maximum of $1.6 \sigma$ five days before an earthquake of $M_{L}=3.2$. The distance from the measuring station to the epicentre was shorter than the strain radius $(E / D=0.6)$. It then decreased until the seismic event took place. That might be explained by stress relaxation associated with the earthquakes but not by dilution 
of thermal water with rainwater, because there was no rainfall during that period.

Another two radon peaks of $1.8 \sigma$ and $1.7 \sigma$ occurred approximately one month before an earthquake of $M_{L}=2.1$ (fig. 2). The measuring station was outside the area, defined by the strain radius $(E / D=2.1)$. The influence of this earthquake on the radon anomaly was considered less significant.

The last radon increase of $1.9 \sigma$ occurred one and a half months before an earthquake of magnitude $M_{L}=1.6$ (figs. 2 and 6). The distance from the measuring station to the epicentre corresponded to the strain radius $(E / D=1)$.

No significant variation of radon concentration was found from the middle of January to April 2003 (fig. 2), although four consecutive earthquakes occurred during this period. This could be explained by the fact that the measuring station was outside the area, defined by the strain radius $(E / D=2.1,1.5,2.0,2.3$, respectively).

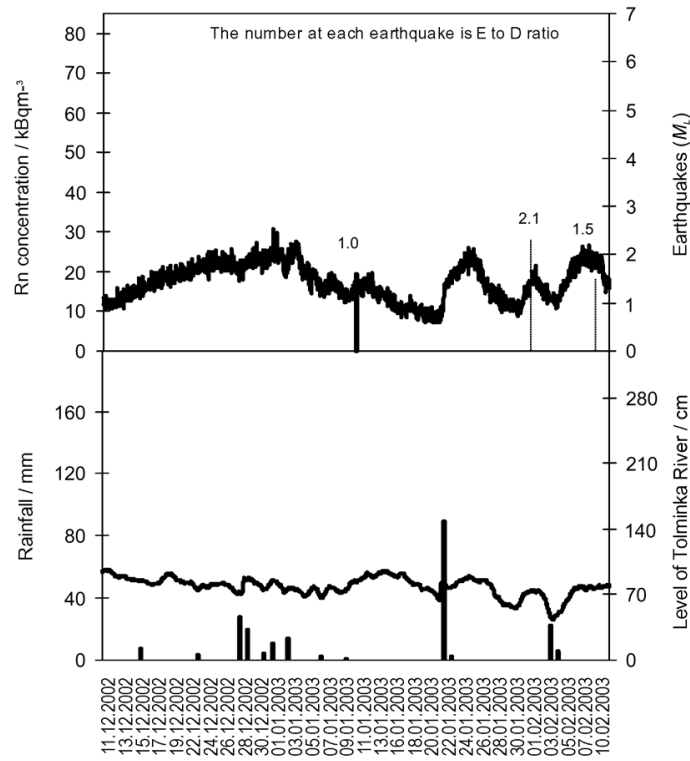

Fig. 6. $\mathrm{Rn}$ concentration $\left(\mathrm{kBqm}^{-3}\right)$, earthquakes $\left(M_{L}\right)$, rainfall $(\mathrm{mm})$ and the level of the Tolminka River $(\mathrm{cm})$ in the thermal spring at Zatolmin between December 2002 and February 2003.
Our explanation of radon anomalies and their relation to earthquakes, as well as our interpretation of physical processes causing radon variations, will be strengthened after a longer monitoring period.

\subsection{Measuring station at Bled}

Thermal water at Bled wells out in a basin at the Grand Hotel Toplice. It displays $\mathrm{CO}_{2}$ bubbling activity. The average water temperature between May 2002 and April 2003 was $21.9 \pm$ $\pm 0.2^{\circ} \mathrm{C}$. The water is used for bathing and drinking. Instruments are installed at the bottom of the collecting basin, from where the water is released into the swimming-pool.

The average electrical conductivity of spring water between May 2002 and April 2003 was $869 \pm 21 \mu \mathrm{Scm}^{-1}$. No correlation between meteorological parameters and electrical conductivity or water temperature was observed (fig. 7). The only two earthquakes during the monitoring period occurred on May 22, 2002 with a $M_{L}$ of 0.9 and on June 7, 2002 with a $M_{L}$ of 1.2 (table I). In both cases, the measuring station was outside the area, defined by the strain radius $(E / D=2.0)$. No anomalous values of electrical conductivity or water temperature were detected at that time. The electrical conductivity suddenly decreased from 895 to $860 \mu \mathrm{Scm}^{-1}$ in September 2002 and then returned to the previous value in April 2003, which cannot be attributed to seasonal variations, because of the rapidity of the changes; on the other hand water temperature changes were smaller and of shorter duration.

A longer monitoring period is required to explain this decrease in electrical conductivity. The correlation coefficient between electrical conductivity and water temperature was 0.63 . The $\mathrm{Ca}, \mathrm{K}, \mathrm{Na}, \mathrm{Mg}$ and $\mathrm{Si}$ concentrations decreased in the period from December 2002 to March 2003, when no significant precipitation was recorded (figs. 7 and 8). Thus, inflow of $\mathrm{Ca}, \mathrm{Mg}$, $\mathrm{K}, \mathrm{Na}$ and $\mathrm{Si}$ to thermal water resevoir from meteoric water was much reduced during this time.

$E h$ and $p H$ values measured monthly from February to May 2003 were relatively stable, and averaged $220 \mathrm{mV}$ and 6.7, respectively. 


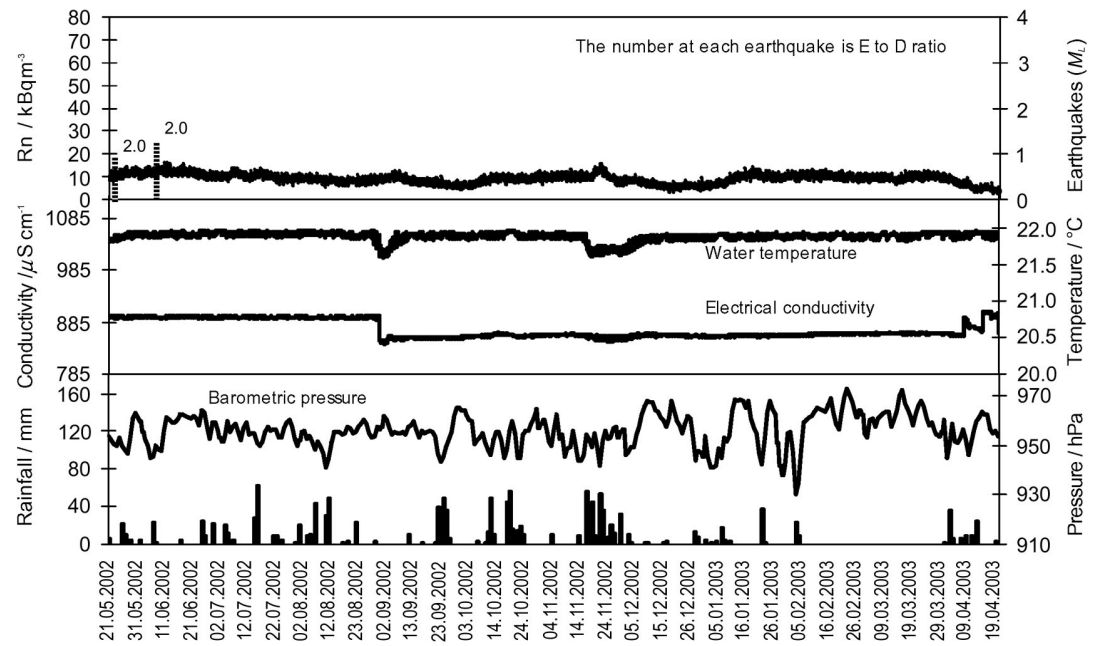

Fig. 7. Geochemical data measured in the thermal spring at Bled between May 2002 and April 2003. The first diagram (starting from the top) shows radon concentration $\left(\mathrm{kBqm}^{-3}\right)$ and earthquakes $\left(M_{L}\right)$. E is the distance between the measuring station and the epicentre, while is $D$ the strain radius. The second diagram shows electrical conductivity $\left(\mu \mathrm{Scm}^{-1}\right)$ and water temperature $\left({ }^{\circ} \mathrm{C}\right)$, and the third diagram shows rainfall $(\mathrm{mm})$ and barometric pressure $(\mathrm{hPa})$.

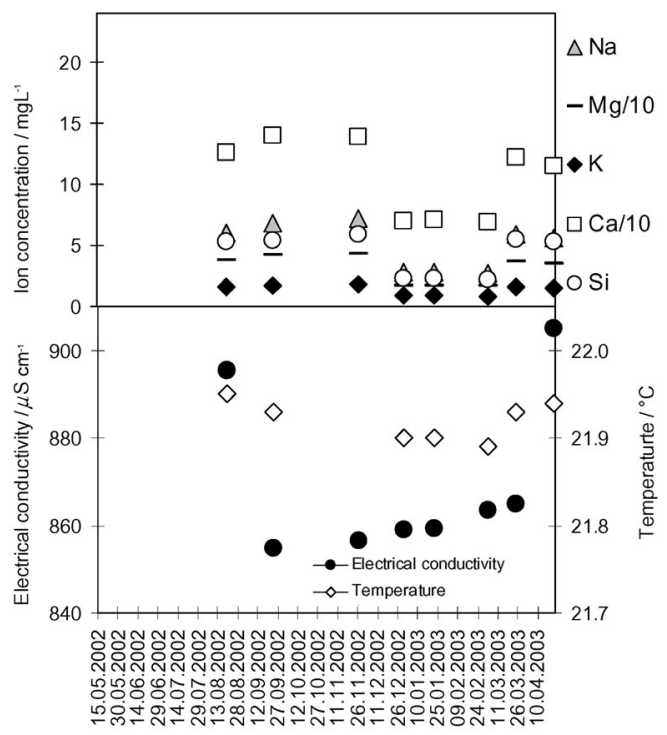

Fig. 8. Ion concentrations $\left(\mathrm{mgL}^{-1}\right)$, electrical conductivity $\left(\mu \mathrm{Scm}^{-1}\right)$ and water temperature $\left({ }^{\circ} \mathrm{C}\right)$ in the thermal spring at Bled between May 2002 and April 2003.
The average radon concentration between May 2002 and April 2003 was $9 \pm 2 \mathrm{kBqm}^{-3}$. The radon curve showed a trend of slow decrease with small fluctuations. Data accumulated in a quiescent period is useful as a baseline for recognizing possible precursory changes in the future (Nakamura and Wakita, 1985).

\section{Conclusions}

Much of the variation in radon concentration, electrical conductivity, water temperature, ion concentration, $p H$ and $E h$ in the thermal spring at Zatolmin could be assigned to nontectonic causes, including rainfall and the level of the Tolminka River. In the period between June and November 2002, radon concentration was always above $1 \sigma$ and a few times it even reached $2 \sigma$ over the mean value. But in the period between January and April 2003 radon level was constantly up to $1 \sigma$ below the mean value. If precipitation were the main cause for in- 
creased radon level between June and November 2002, then we would expect a larger increase in radon concentration also during the rainfall in December 2002 and from March to April 2003. Thus, radon behaviour cannot be simply related to meteorological factors. In the period with radon levels exceeding $1 \sigma$ over the mean value, six earthquakes with $E / D$ ratio equal or below 1 occurred while in the period with radon concentration up to $1 \sigma$ below the mean value, three earthquakes with $E / D$ ratio above 1 occurred. This fact is in accordance with the theory of the stress-strain field defined by Dobrovolsky. Our interpretation of physical processes causing radon variations will be improved after a longer monitoring period.

Changes in electrical conductivity and water temperature in the thermal spring at Bled showed no correlation with meteorological parameters. Fluctuations of radon concentration were insignificant due to low seismic activity over the period. Data accumulated in a quiescent period will be useful as a baseline for recognizing possible precursory changes in the future.

Continuous monitoring (frequency of sampling and analyses once per hour) of radon concentration, electrical conductivity and water temperature in spring waters, together with grab sampling and analyses (once per month or immediately after the seismic event) of dissolved ion concentrations constitute an important basis for studying the relationship between the measured parameters and seismic activity. Further monitoring of geophysical and geochemical parameters at Zatolmin and Bled thermal springs is required to be able to better distinguish variations due to hydro-meteorological and seasonal changes from those caused by tectonic events.

\section{Acknowledgements}

This study was financed by the Ministry of Education, Science and Sport of Slovenia. The cooperation of the personnel at Grand Hotel Toplice at Bled, especially of Mr. Biol is gratefully acknowledged. The authors thank Mr. Sovdat and other divers of the Zatolmin Divers Club, for gas and water sampling in the thermal spring at Zatolmin.

\section{REFERENCES}

Bella, F., P.F. Biagi, M. Caputo, E. Cozzi, G. Della Monica, A. ERmini, E.I. GordeEZ, Y.M. KhatKeVich, G. Martinelli, W. Plastino, R. Scandone, V. SGrigna and D. ZiLPIMIANi (1998): Hydrogeochemical anomalies in Kamchatka (Russia), Phys. Chem. Earth., 23 (9/10), 921-925.

Biagi, P.F., A. ERmini, S.P. Kingsley, Y.M. KhatKevich and E.I. GoRdeEv (2000): Possible precursors in groundwater ions and gases content in Kamchatka (Russia), Phys. Chem. Earth. (A), 25 (3), 295-305.

Di Bello, G., J. Heinicke, U. Koch, V. Lapenna, M. MaCChiato, G. Martinelli and S. Piscitelli (1998): Geophysical and geochemical parameters jointly monitored in seismic area of Southern Apennines (Italy), Phys. Chem. Earth., 23, (9/10), 909-914.

Dobrovolsky, I.P., S.I. ZubKov and V.I. Miachin (1979): Estimation of the size of the earthquake preparation zones, Paleoph., 117, 1025-1044.

Dongarra, G., S. Hauser, P. Censi and M. Brai (1995): Water chemistry, $\delta 13 \mathrm{C}$ and ${ }^{222} \mathrm{Rn}$ activity in groundwaters of Western Sicily, Nucl. Geophys., 9 (5), 461470.

Etiope, G. and G. Martinelli (2002): Migration of carrier gases in the geosphere: an overview, Phys. Earth Planet. Inter., 129, 185-204.

Favara, R., F. Grassa, S. Inguaggiato and M. Valenza (2001): Hydrogeochemistry and stabile isotopes of thermal springs: earthquake-related chemical changes along Belice Fault (Western Sicily), Appl. Geochem., 16, $1-17$.

Heinicke, J., U. Koch and G. Martinelli (1995): $\mathrm{CO}_{2}$ and radon measurements in the Vogtland area (Germany) A contribution to earthquake prediction research, Geophys. Res. Lett., 22 (7), 771-774.

Heinicke, J., F. Italiano, V. Lapenna, G. Martinelli and P.M. Nuccio (2000): Coseismic geochemical variations in some gas emissions of Umbria Region (Central Italy), Phys. Chem. Earth (A), 25 (3), 289-293.

Igarashi, G., S. Saeki, K. Takahata, K. Sumikawa, S. TASAKA, Y. SASAKI, M. TAKAHASHI and Y. SANO (1995): Groundwater radon anomaly before the Kobe earthquake in Japan, Science, 269, 60-61.

IRWIN, W.P. and I. BARNES (1980): Tectonic relations of carbon dioxide discharges and earthquakes, J. Geophys. Res., 85 (B6), 3115-3121.

KING, C.Y. (1978): Radon emanation on San Andreas Fault, Nature, 271, 516-519.

KING, C.Y. (1980): Geochemical measurements pertinent to earthquake prediction, J. Geophys. Res., 85 (B6), 3051.

KING, C.Y. (1986): Gas geochemistry applied to earthquake prediction: An overview, J. Geophys. Res., 91 (B12), 12269-12281.

KING, C.Y. (1989): Gas-geochemical approaches to earthquake prediction, in Proceedings of International Workshop on Radon Monitoring in Radioprotection, Environmental Radioactivity and Earth Sciences, April 3-14, 1989, Trieste (Italy).

King, C.Y., D. BASLER, T.S. PREsSER, W.C. Evans and L.D. WHITE (1994): In search of earthquake related hydrologic and chemical changes along Hayward Fault, Appl. Geochem., 9, 83-91. 
KocH, U. and J. HeINICKE (1994): Radon behaviour in mineral spring water of Bad Brambach (Vogtland, Germany) in the temporal vicinity of the 1992 Roermond earthquake, the Netherlands, Geol. Mijnbouw, 73, 399-406.

Koch, U., J. HeInICKe and M. VossberG (2003): Hydrogeological effects of the latest Vogtland-NW Bohemian swarmquake period (August to December 2000), J. Geodin., 35, 107-123.

Martinelli, G. (1993): Fluidodynamical and chemical features of radon 222 related to total gases: implications for earthquake predictions, in Proceedings of an Advisory Group Meeting, September 9-12, 1991, Vienna, IAEA TECDOC-726, 48-62.

Monnin, M.M. and J.L. SEIDEL (1997): Physical models related to radon emission in connection with dynamic manifestations in the upper terrestrial crust: a review, Rad. Meas., 28 (1-6), 703-712.

NAKAMURA, Y. and H. WAKITA (1985): Precise temperature measurement of groundwater for earthquake prediction study, Pure Appl. Geophys., 122, 164-174.

Planinič, J., V. RADOLIČ and Ž LAZANIN (2001): Temporal variations of radon in soil related to earthquakes, Appl. Rad. Isot., 55, 267-272.

POLJAK, M., M. ŻVČIČ and P. ZuPANČIČ (2000): The seismotectonic characteristic of Slovenia, Pure Appl. Geophys., 157, 37-55.

RIBARIČ, V. (1982): Seismicity of Slovenia - Catalogue of earthquakes (792 A.D.-1981), Seismol. Surv. SR-Slovenia, Series A, 1, p. 649.

Shimizu, I., H. Osawa, T. Seo, S. Yasuike and S. Sasaki (1996): Earthquake-related ground motion and groundwater pressure change at the Kamaishi Mine, Eng. Geol., 43, 107-118.

Singh, M., M. Kumar, R.K. JaIn and R.P. Chatrath (1999): Radon in ground water related to seismic events, Rad. Meas., 30, 465-469.

Thomas, D. (1988): Geochemical precursors to seismic activity, Pure Appl. Geophys., 126, 241-266.
ToutAin, J.P. and J.C. BAUBRON (1999): Gas geochemistry and seismotectonics: a review, Tectonophysics, 304, 1-27.

VÁRHEGYI, A., I. BARANYI and G. SOMOGYI (1986): A model for the vertical subsurface radon transport in 'geogas' microbubbles, Geophys. Trans., 32 (3), 235-253.

VIRK, H.S. and V. WALIA (2001): Helium/radon precursory signals of Chamoli Earthquake, India, Rad. Meas., 34, 379-384.

WAKITA, H. (1978): Earthquake prediction and geochemical studies in China, Chin. Geophys., 1, 443-457.

WAKITA, H., Y. NAKAMURA and Y. SANO (1985): Groundwater radon variations reflecting changes in regional stress fields, Earthquake Predict. Res., 3, 545-557.

WAKITA H., Y. NAKAMURA and Y. SANO (1986): Background fluctuations in groundwater radon observation, J. Phys. Earth., 34, 81-89.

Woith, H., C. Milkereit, J. Zschau, V. Igumnov, A. AVANESSIAN and S. BALASSANIAN (1998): Thermal and mineral waters as natural strain sensors, in Book of $A b$ stracts of XXVI General Assembly of the European Seismological Commission, August 23-28, 1998, Tel Aviv (Israel).

ZHANG, W. (1999): Research on relationships between escaping radon and stress-strain of the crust, Nuovo $\mathrm{Ci}$ mento, 22 C (3/4), 437-442.

ZmazeK, B., J. Vaupotič, M. Žvčič, U. Premru and I. KoBAL (2000): Radon monitoring for earthquake prediction in Slovenia, Fizika B (Zagreb), 9 (3), 111-118.

ZMaZeK, B., F. Italiano, M. ŽıvČı̌, J. VAupotič, I. Kobal and G. Martinelli (2002a): Geochemical monitoring of thermal waters in Slovenia: relationships to seismic activity, Appl. Rad. Isot., 57, 919-930.

ZMaZeK, B., ŻVČIČ, J. VAupotič, M. Bidovec, M. PoljaK and I. Kobal (2002b): Soil radon monitoring in the Krško Basin, Slovenia, Appl. Rad. Isot., 56, 649-657.

ZMAZEK, B., L. Todorovski, S. DŽEROSKI, J. VAuPotič and I. Kobal (2003): Application of decision trees to the analysis of soil radon data for earthquake prediction, Appl. Rad. Isot., 58, 697-706. 